\title{
Delivering high-quality child health care in general practice
}

This month's BJGP reports an observational study of screening for testicular descent which makes the claim that such screening is worthwhile in older boys. ${ }^{1}$ The authors advocate the reinstatement of the previous screening regimen for testicular descent at 9 months and 3.5 years. ${ }^{2}$ Is this a sensible recommendation?

The current UK National Screening Committee evidence-based programme recommends screening for undescended testes (UDT) at birth and at 8 weeks but not for older boys. A previously published audit of delayed orchidopexy concluded that ascent of a previously scrotal testis was the likely cause for late diagnosis of UDT rather than a failure of screening. ${ }^{3}$ This would explain the consistently high mean age at which boys undergo orchidopexy reported from all over the world, despite the introduction of 'aggressive' UDT screening. ${ }^{4}$

It is increasingly recognised that ascending testes are more common than previously thought and are more likely to have a history of being retractile. ${ }^{5}$ Although most retractile testes do not require surgery, ${ }^{6}$ they should not be considered a normal variant, as some can ascend in older boys necessitating orchidopexy. The regular follow-up of boys with retractile testes is recommended rather than the introduction of a more general screening programme for older boys. ${ }^{5}$

\section{SCREENING AND EXAMINATION}

Screening for early childhood illness is important and can be done well in general practice. For most children, the early detection of congenital conditions, such as hip dysplasia, cataract, coarctation of the aorta, and UDT, can make a real difference to their future health. The key issues for us as GPs are the timing of the screening, our competency to undertake the necessary examinations, and the practice resources required to deliver the programme.
As the optimal management of retractile and ascending testes remains controversial, we believe that our current focus should be on ensuring our competency to carry out the 6- to 8-week examination, actively following up all infants who default on their screening appointments, and opportunistically screening any boy at a later date if there is parental concern. ${ }^{2}$

\section{QUALITY STANDARDS}

The delivery of high-quality child health care remains a core component of general practice. All GPs should be competent and be able to demonstrate that they are proficient in recognising and managing acute and chronic illness in children, and in organising their practices to administer timely health promotion and preventative care to all children and their parents. Developing and maintaining competence in the care of children and young people requires high standards of clinical training, regular clinical exposure, continuing education, and audit of performance.

The care of children and young people needs to be adequately reflected within accreditation, governance, the Quality and Outcomes Framework, and research in general practice. ${ }^{8}$ We believe the Royal College of General Practitioners (RCGP) should lead on making child health a priority area for primary care by assuming responsibility for developing a wider range of quality standards in general practice for children and young people.

Setting quality standards for the care of children and young people is not new for the RCGP. Extensive work has already been undertaken by the RCGP Adolescent Health Primary Care Society and the Royal College of Nursing through its Getting it Right for Teenagers in Your Practice campaign. ${ }^{9}$ In addition, an RCGP toolkit for Safeguarding Children and Young People in general practice ${ }^{10}$ has been developed in collaboration with the National Society for the Prevention of Cruelty to Children.
New RCGP quality standards for all children and young people should be based on the best available evidence and set alongside national priorities, such as the National Service Framework for Children, Young People and Maternity Services. ${ }^{11}$

\section{RECOMMENDATIONS FOR IMPROVEMENTS}

It is our view that the RCGP should also support an increase in the leadership capacity for child health for general practice. Every practice, federation, or commissioning group should have a GP with a special interest in child health who can lead on safeguarding, clinical standards, and organisation as well as the configuration of practice-based services for children and young people. In addition, the RCGP should consider the introduction of a diploma or higher accreditation in child health specifically aimed at the cohort of GPs in their first 5 years in practice. This would give an opportunity for those doctors to develop a special interest in child health, increase future leadership capacity, and send a strong signal to other potential providers of primary health care to children that the RCGP is determined to build on and improve the delivery of GP-led care to children and young people.

\section{Nigel Mathers,}

Professor of Primary Medical Care, University of Sheffield and Principal in General Practice.

\section{Anthony Harnden,}

University Lecturer in General Practice, University of Oxford and Principal in General Practice.

\section{Provenance}

Commissioned, not externally peer reviewed.

\section{REFERENCES}

1. Neilson AG, Walker GM. Screening of testicular descent in older boys is worthwhile: an observational study. $\mathrm{Br} \mathrm{J}$ Gen Pract 2011; 61: 173-177.

2. Hall D, Elliman D. Health for all children. Revised 4th edn. Oxford: Oxford University Press, 2006.

3. Thayyil S, Shenoy M, Agrawal K. Delayed orchidopexy: failure of screening or ascending testis. Arch Dis Child 
2004; 89: 890-891. doi:10.1136/adc.2003.045070.

4. Lamah M, McCaughey ES, Finlay FO, Burge DM. The ascending testis: is late orchidopexy due to failure of screening or late ascent? Pediatr Surg Int 2001; 17: 421-423. doi:10.1007/s003830000535

5. Guven A, Kogan BA. Undescended testis in older boys: further evidence that ascending testes are common. $J$ Paediatr Surg 2008; 43: 1700-1704.

6. Stec AA, Thomas JC, De Marko RT, et al. Incidence of testicular ascent in boys with retractile testes. J Urolog 2007; 178: 1722-1725.

7. Agarwal PK, Diaz M, Elder JS. Retractile testis - is it really a normal variant? J Urology 2006; 175: 1496-1499.

8. Royal College of General Practitioners. RCGP Child Health Strategy 2010-2015. London: Royal College of General Practitioners, 2010.
http://www.rcgp.org.uk/pdf/CIRC_RCGP_Child_Health Strategy_2010_2015_FINAL.pdf (accessed 9 Feb 2011).

9. Royal College of Nursing. Getting it right for teenagers in your practice. 2007.

http://www.rcn.org.uk/_data/assets/pdf_file/0008/78542 001798.pdf. (accessed 28 Jan 2011).

10. Royal College of General Practitioners. Safeguarding children and young people: a toolkit for general practice 2009 revision.

http://www.rcgp.org.uk/docs/CIRC_Toolkit\%202009\%20 final (accessed 28 Jan 2011)

11. UK, Department of Health. National service framework for children, young people and maternity services: executive summary. London: Department of Health, 2004.

http://www.dh.gov.uk/en/Publicationsandstatistics/Public ations/PublicationsPolicyAndGuidance/DH_4089100 (accessed 28 Jan 2011).
DOI: 10.3399/bjgp11X561104

ADDRESS FOR CORRESPONDENCE

Nigel Mathers

Academic Unit of Primary Medical Care, University of Sheffield, Samuel Fox House, Northern General Hospital, Herries Road, Sheffield, S5 7AU.

E-mail: n.mathers@sheffield.ac.uk

\section{Revalidation:}

\section{a critical perspective}

As the stadium for the 2012 Olympics rises brick by shining brick against the London skyline, the apparatus for revalidation of doctors in the UK is currently being constructed to a similar timetable (although tellingly, no date has been set for its opening ceremony). ${ }^{1}$ Revalidation's goals appear to be threefold: restore public trust in the medical profession; support professional development in all doctors; and weed out the bad apples..$^{2-4}$ Many have pointed out that these goals may conflict (for example, professional development is a formative and supportive process, while dealing with unacceptably poor practice must surely be summative and judgemental) and that the evidence base linking the proposed input (5yearly assessment of a portfolio) with the desired outcome (better, safer care for patients) is all but absent. ${ }^{5-8}$

\section{SPARSE EVIDENCE BASE}

The research literature on revalidation is indeed sparse. For example, a single randomised trial in 66 Scottish GPs compared a light-touch, 'criterion-based' model with a more comprehensive, 'educational outcome' model; there were no differences in what was recorded in the portfolios or in self-reported changes in practice, but participants preferred the former model. ${ }^{9}$ In this study of volunteers, $20 \%$ of doctors did not hand in their portfolio and impact on patient care was not measured. Professional certification status in the US has been depicted as having led to improvements in quality of care, but online responses pointed out that association in an uncontrolled study does not prove causation. ${ }^{10}$

We could find only one paper which applied an explicit theoretical model of professional practice to revalidation: 6 years ago, Paul Thomas argued in this Journal that:

'Shipman could have passed tests for medical competence. It was someone unafraid to ask 'why do so many of your patients die?' that found him out ... Revalidation must lead to an environment where supportive asking of uncomfortable questions becomes the norm."

Thomas considered this crucial questionasking at three levels: individual (Schon's 'reflective practitioner'), organisational (Senge's 'learning organisation') and system (Lave and Wenger's 'community of practice'). He concluded that individual revalidation, however well implemented, was only one component of a process which should also include organisational and system assessments.

\section{AN UNEASY PROFESSION}

In The Doctor's Dilemma, George Bernard
Shaw reminded us that 'All professions are a conspiracy against the laity'. Perhaps in acknowledgement of their undeniable conflict of interest, doctors' official opposition to revalidation has been muted. But anecdotally, and in the relative safety of the online blog or letter to the 'GP freebies', doctors are predicting that revalidation will be an inefficient, deprofessionalising, and overly bureaucratic process which for those approaching retirement age will not be worth the candle. Once it becomes compulsory, they say, they will not carry on.

Tim van Zwanenberg perceptively questioned whether revalidation would be sufficiently 'sensitive (identify poor performance), specific (identify educational needs), valid (reflect actual clinical practice), or reliable (behave consistently across cohorts of doctors)'.2 Important though these attributes of revalidation as a process are, there are some even more fundamental, extra-individual questions about revalidation as a policy. Where did it come from? What is its ideological basis? Whose interests will it serve? What power shifts are implicated in its introduction? What language is used in the policy and what does this symbolise? How, for example, is 'good professional practice' defined and framed? What is not talked about and why?

\section{A POLICY 'OF ITS TIME'}

Kingdon proposed that the policymaking 